\title{
Crustal velocity structures and their tectonic implications in different tectonic block regions of the Chinese mainland *
}

\author{
Xiankang Zhang* Yonghong Duan Jinren Zhao Chengke Zhang Shixu Jia \\ Jianshi Zhang Fuyun Wang Zhuoxin Yang and Suzhen Pan \\ Geophysical Exploration Center, China Earthquake Administration, Zhengzhou 450002, China
}

\begin{abstract}
In this paper, the typical velocity structures and average velocities of the crust in six different active tectonic block regions are presented on the basis of previous studies and their tectonic implications are discussed. The results show that different tectonic units have different features of crustal velocity structures. In general, there are low velocity distributions in the crust in regions with strong tectonic activities, and the scales of low velocity distributions are related to the tectonic activities. The average velocities are relatively low in such regions. This reflects strong crustal deformation and the variations of states of matter in the crust resulting from strong tectonic movements. These regions are also seismically active zones frequented by strong earthquakes. Therefore, studying crustal velocity structures of these regions is of great importance to understanding crustal geodynamic process and seismogenic tectonic background.
\end{abstract}

Key words: tectonic block; wide angle reflection and refraction experiments; velocity structure; crust model CLC number: P315.2

Document code: A

\section{Introduction}

Different tectonic styles exist simultaneously on the Chinese mainland due to the pinching actions from India, Philippine and Pacific Ocean plates and the deep geodynamic action in Eurasia plate, which control the spatial distribution image of strong earthquakes on the Chinese mainland. One of the distinct features is the intense development of huge Late Quaternary active faults, which divided the Chinese mainland into several active tectonic blocks in different orders, and most strong earthquakes on the Chinese mainland occurred just on the boundaries of these blocks. Based on the tectonic activities since Late Quaternary period, the Chinese mainland and its adjacent areas can be divided into six first-order active tectonic block regions, i.e., Qinghai-Tibet, South China, North China, Northeast Asia, Xiyu and Yunnan-Myanmar, which can be further divided based on their local tectonic features (Zhang et al, 2003). The results of wide angle reflection and refraction profiles, which are distributed in different re-

\footnotetext{
* Received 2 April 2009; accepted in revised form 11 May 2009; published 10 August 2009.

^Corresponding author. e-mail: xkzhang@public2.zz.ha.cn
}

gions and carried out at different times, show distinct differences of the crustal structures among these blocks, which are manifested mainly in layered features of the crust, structural features of the mid- and lower- crust, scales of heterogeneity of crustal structures, low velocity distributions and topography of interfaces in the crust. The study of structural properties of active tectonic blocks can help to understand the possibility of decoupling among these active tectonic blocks at different depth levels, distribution features of strong earthquakes and deep seismogenic tectonic backgrounds. In this paper, the typical velocity structures of the crust and average crustal velocities of the six active tectonic block regions mentioned above are presented on the basis of the results of wide angle reflection and refraction experiments carried out on the Chinese mainland, and the tectonic characters and their dynamic implications are discussed. Some local and special features of the crustal structures have not been discussed due to complexity of tectonics, even among different divisions of the same tectonic block, on the Chinese mainland. The crust is divided into two parts for discussion in this paper, i.e., the upper crust and the lower crust. 


\section{Wide angle reflection and refraction profiles on the Chinese mainland}

Large-scale wide angle reflection and refraction experiments have been carried out in China since the occurrence of Xingtai earthquake in 1966. The observation layouts of the deep seismic sounding (DSS) profiles carried out in the 1970s and 1980s were not perfect enough and the receiver spacing was relatively large due to limited seismic instruments. Generally speaking, the DSS profiles carried out since the 1990s have relatively perfect observation layouts. The studies carried out in some major areas (such as earthquake risk regions and volcanic regions) and on some important scientific problems (such as seismic active faults) have propelled deep crust structure explorations in China. The total length of the wide angle reflection and refraction profiles completed on the Chinese mainland is about $40000 \mathrm{~km}$. Figure 1 shows the locations of these profiles, most of which are located in North China. The seismic data, obtained from these wide angle reflection and refraction experiments in different tectonic blocks, provide an important basis for constructing crustal structure models. Figure 2 shows the typical seismic record sections obtained in different tectonic regions of the Chinese Mainland.

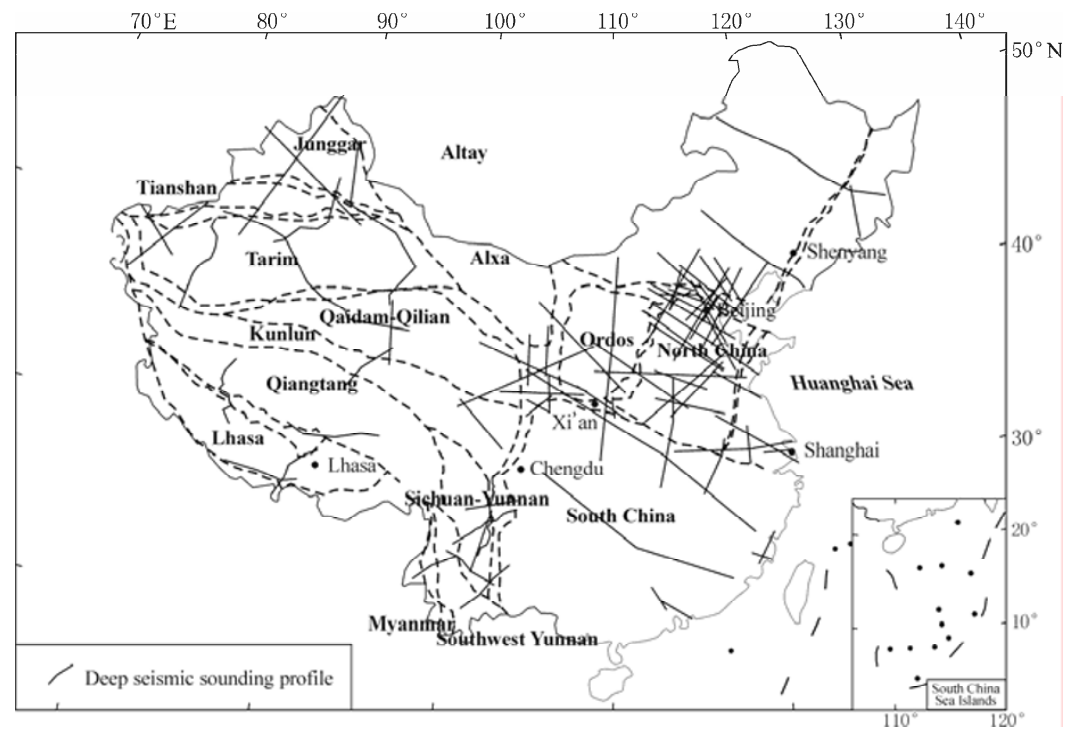

Figure 1 Active tectonic block regions and locations of wide angle reflection and refraction profiles (partially based on Zhang et al, 2003).
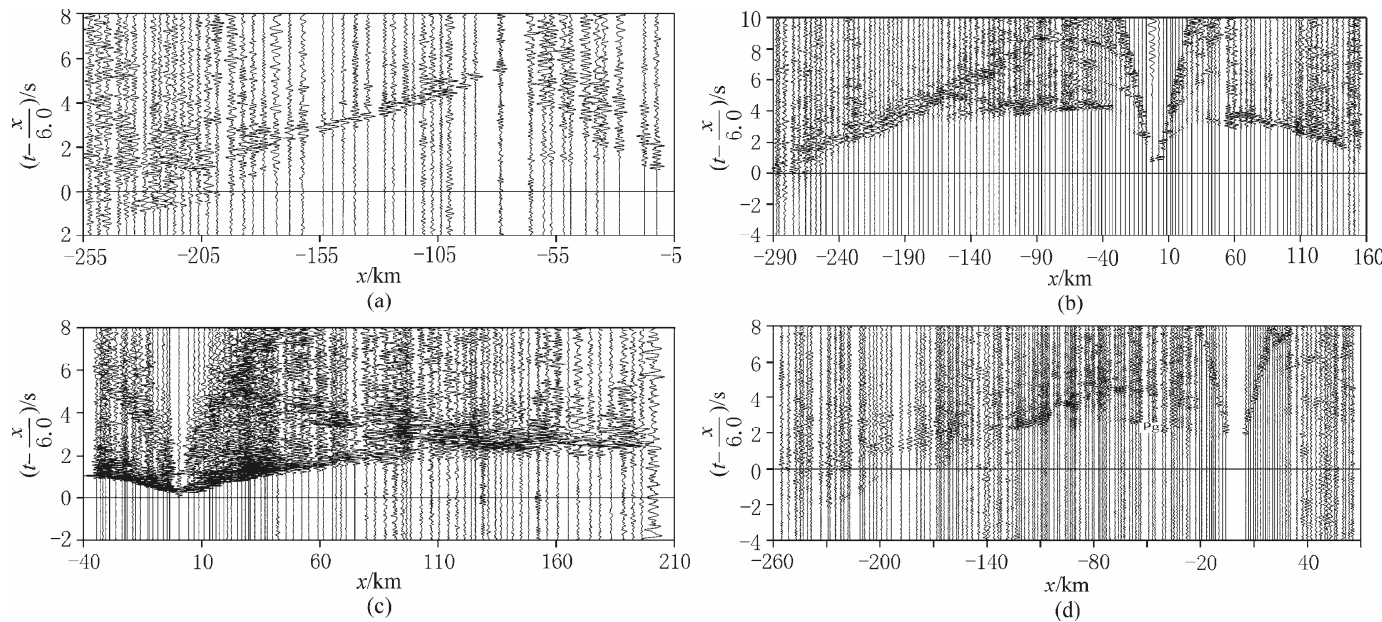

Figure 2 Typical seismic record sections in different tectonic blocks. (a) Ordos; (b) Junggar basin; (c) Northeastern margin of Qinghai-Tibet plateau; (d) North China plain. 


\section{Crustal velocity structures in different tectonic block regions}

\subsection{Crustal velocity struct in Qinghai-Tibet pla- teau tectonic block region}

The deep crust structure and geodynamic process of Qinghai-Tibet plateau are important problems attracting the attention of geoscientists worldwide. Recently the studies on the uplift mechanism and tectonic evolution process of Qinghai-Tibet plateau have been intensified, and close attention has been paid to the mechanism of deep crustal tectonic deformation of the northeastern margin of Qinghai-Tibet plateau. A lot of studies on the crust and upper mantle structures in Qinghai-Tibet plateau, its northeastern margin and eastern area have been carried out by use of DSS technique. The wide angle reflection and refraction profiles completed in these regions include Damxung-Yadong, Pumocuo-Dingjie -Peigucuo, Selincuo-Naqu-Yaanduo, Cuoqin-Gaize-Sangehu, Benzilan-Tangke, Zhubalong-Zizhong, Maqin-Lanzhou-Jingbian and Barkam-Luqu-Gulang profiles. The results of these profiles show the differences in crustal structures between different tectonic blocks. The velocity structures of the crust in Qiangtang-Lhasa, Qaidam-Qilian, Songpan-Garze and West Qinling-East Kunlun tectonic blocks of Qinghai-Tibet region are discussed respectively here.

\subsubsection{Crustal velocity structure of Qiangtang-Lhasa tectonic block}

The results of Damxung-Yadong, Pumocuo -Dingjie-Peigucuo, Selincuo-Naqu-Yaanduo and Cuoqin-Gaize-Sangehu wide angle reflection and refraction profiles (Teng, 1985; Cui et al, 1990; Lu and Wang, 1990; Yin et al, 1990; Liu et al, 1990; Wu et al, 1991) indicate that the crust in Qiangtang-Lhasa tectonic block shows obviously layered structure and distinct lateral variation, especially on the boundaries between active tectonic blocks. This kind of lateral variations of crustal structures is usually revealed in velocity decrease of seismic waves or dislocations of the Moho discontinuity. The average velocity of the crust there is about $6.20-6.30 \mathrm{~km} / \mathrm{s}$, and the velocity of the uppermost mantle is about $8.10-8.20 \mathrm{~km} / \mathrm{s}$ (Figures $3 \mathrm{a}$ and $3 \mathrm{~b}$ ). The average velocity of the crust in the Himalayas terrain is slightly lower than that in other terrains. The thickness and velocity of the basement vary obviously. An expansive low velocity layer is found at the bottom of the upper crust, in which the velocity is about $5.60-5.70 \mathrm{~km} / \mathrm{s}$ (Figures $3 \mathrm{a}$ and $3 \mathrm{~b}$ ). It corresponds to a high conductiv- ity layer, and is inferred to be a water-bearing tectonic detachment. The velocity in the mid part of the crust is about $6.30-6.60 \mathrm{~km} / \mathrm{s}$, without distinct lateral variation. Another low velocity layer can be found in South Tibet at a depth of $50 \mathrm{~km}$ (Figures $3 \mathrm{a}$ and $3 \mathrm{~b}$ ), which may be inferred as a water-bearing detachment with partial melting. The lower crust behaves as a velocity gradient layer. In general, the crust is $70-80 \mathrm{~km}$ thick, and the average velocity of the crust is about $6.2 \mathrm{~km} / \mathrm{s}$ in Qinghai-Tibet plateau.

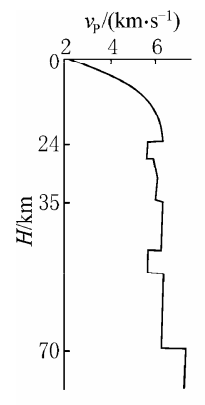

(a)

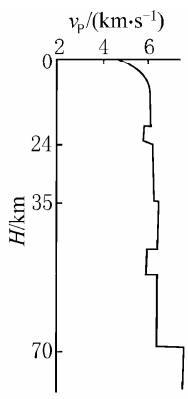

(b)

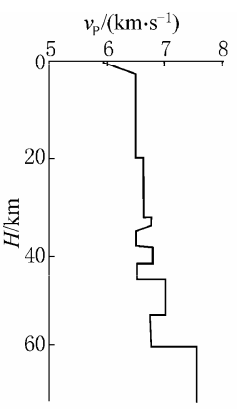

(c)

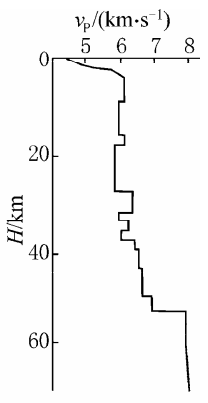

(d)
Figure 3 Typical velocity-depth functions in Qinghai-Tibet plateau. (a) Qiangtang tectonic block; (b) Lhasa tectonic block; (c) Qaidam-Qilian tectonic block; (d) Songpan-Garze tectonic block.

\subsubsection{Crustal velocity structure of Qaidam-Qilian tectonic block}

Figure $3 \mathrm{c}$ shows the velocity-depth function of Zeku shot of Maqin-Lanzhou-Jingbian profile, which reflects the structural features of the crust in the transition zone between Bayanha and Kunlun tectonic blocks (Li et al, 2002). The basement there is $4 \mathrm{~km}$ deep. The thickness of the upper crust is about $21 \mathrm{~km}$ and the velocity is about $6.3 \mathrm{~km} / \mathrm{s}$. The lower crust is $39 \mathrm{~km}$ thick, with a velocity of about $6.50-7.00 \mathrm{~km} / \mathrm{s}$. There is a low velocity laminar structure with a velocity of $6.40 \mathrm{~km} / \mathrm{s}$ in the lower crust. The Moho is $60 \mathrm{~km}$ deep, and it behaves as a structurally complicated transition zone. The average velocity of the crust is about $6.18 \mathrm{~km} / \mathrm{s}$. The thickening of the crust and low average velocity of the crust mainly result from the alternately high and low velocity laminated structure and thickening of the lower crust, which indicates complicated tectonic deformation in this region. This kind of crustal deformation mainly occurred in the lower crust, which is characterized by the increase of the number of tectonic layers, the appearance of low velocity laminas and the fluctuation of interfaces. Such complicated tectonic frame is related to the tectonic environment and the history of geological 
evolution in this region ( $\mathrm{Li}$ et al, 2002; Yuan et al, 2004).

\subsubsection{Crustal velocity rstcture of Songpan-Garze tectonic block}

Figure $3 \mathrm{~d}$ shows the typical velocity-depth function of the crust from Tangke and Barkam shots of Benzilan-Tangke profile (Wang et al, 2003). The thickness and velocity of the upper crust are about $27 \mathrm{~km}$ and 6.1 $\mathrm{km} / \mathrm{s}$ respectively in this block. There is a relatively thick low-velocity (about $5.9 \mathrm{~km} / \mathrm{s}$ ) layer from the depth of $10 \mathrm{~km}$ to the bottom of the upper crust. The velocity structure in the lower crust is complicated. There are laminated low velocity structures with a velocity of 5.9 $\mathrm{km} / \mathrm{s}$ in the lower crust. The variation of the crustal thickness mainly results from the variation of the thickness of the lower crust. The thickness of the crust in this tectonic block is about $56 \mathrm{~km}$ and the average velocity of the crust is about $6.10-6.20 \mathrm{~km} / \mathrm{s}$, which is relatively low compared with other tectonic blocks on the Chinese mainland. The Songpan-Garze tectonic block, as a transition zone from Qinghai-Tibet plateau to Yangtze platform, underwent strong tectonic deformation and crust thickening during the rising process centered at Qinghai-Tibet plateau, and a complicated surface tectonic frame was formed (Wang et al, 2003).

\subsubsection{Crustal velocity structure of eastern A'nyemaqen suture belt and its adjacent area}

The eastern A'nyemaqen suture zone, located at the northeastern margin of Tibetan plateau, is an area connecting Songpan-Garze tectonic block, East Kunlun fault zone and Qinling fold zone, therefore, the tectonic background there is very complicated. It involves $\mathrm{Ku}-$ saihu-Maqin fault, Diebu fault and Zhouqu-Liangdang fault. The Zoige basin, located in the northeastern margin of Qinghai-Tibet plateau, is a special tectonic unit, and immediately to its north lays the eastern A'nyemaqen suture zone. A wide angle reflection and refraction experiment and a near vertical reflection profiling were carried out in this region (Gao et al, 2006; Zhang et al, 2007, 2008a). Figures 4a and 4b shows the typical velocity-depth functions of the crust in eastern A nyemaqen suture belt and Zoige basin respectively. The basement in the eastern A'nyemaqen suture belt is $5.6-6.0 \mathrm{~km}$ deep, and it is obviously deeper than that in Zoige basin, where the depth of basement is about $3.0-4.5 \mathrm{~km}$. The velocity-depth function of the crust in this suture belt (Figure 4b) shows that the complexity of the crust structure is mainly revealed in the lower crust, where the structure is characterized by alternately high and low velocity laminas. The lower crust features distinct reflectivity. It corresponds to the results of near vertical reflection profiling carried out in the same region (Gao et al, 2006). The thicknesses of the crust are 52 and $50 \mathrm{~km}$ in the eastern A'nyemaqen suture belt and Zoige basin, respectively, suggesting inconspicuous lateral variation. The average velocity of the crust is about 6.0-6.1 km/s both in the eastern A nyemaqen suture belt and Zoige basin. There are obvious differences in crustal structures between the tectonic blocks in this region. Deformation of interfaces in the crust is strong and low velocity distributions exist in the crust near and on the south of A'nyemaqen suture zone. Especially, the anomalous low velocity distribution beneath the depth of $20 \mathrm{~km}$ to the mid and lower crust implies that the crushed structural features extend at least down to the mid and lower crust (Zhang et al, 2008a; Gao et al, 2006).

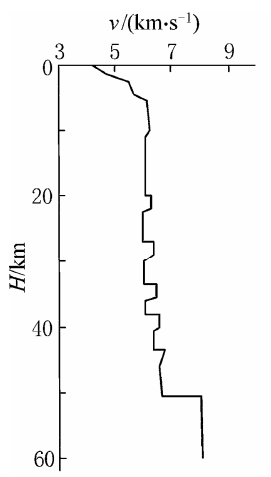

(a)

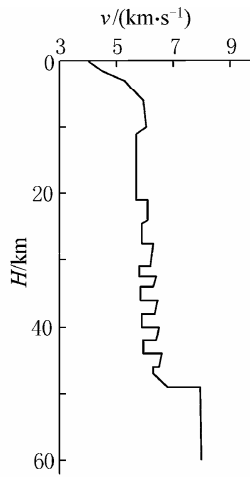

(b)
Figure 4 Typical velocity-depth functions of the crust in eastern A'nyemaqen suture belt and Zoige basin. (a) Zoige basin; (b) Eastern A'nyemaqen suture belt.

\subsection{Crustal velocity structure in the South China tectonic block region}

Several wide angle reflection and refraction profiles have been carried out in the South China tectonic block region, namely Lianxian-Boluo-Gangkou profile (Yin et al, 1999), Ningde-Yongchun profile (Liao et al, 1990), Zhangzhou profile (Zhu et al, 2006) and Fuzhou profile (Zhu et al, 2005). The results are as follows (Figure 5a). The thickness and velocity of the upper crust are $22 \mathrm{~km}$ and $6.0 \mathrm{~km} / \mathrm{s}$, respectively. The velocity of the lower crust is about $6.3 \mathrm{~km} / \mathrm{s}$. There are no low velocity layers in the crust. The thickness of the crust is about $33 \mathrm{~km}$. The crustal structure becomes complicated on its western margin contiguous to the Qinghai-Tibet plateau (Figure 5b), where low velocity layers exist in 
the upper crust and the thickness of the crust is about 40 $\mathrm{km}$. Seismic activity is strong on the side adjoining the Qinghai-Tibet plateau, where the Wenchuan earthquake with magnitude 8.0 occurred. The crustal structure on the southeastern coasts, in the southern part of the South China active tectonic block region, is more complicated than the structure in the interior part (Figure 5c). The thickness of the upper crust here is about $17 \mathrm{~km}$, and its velocity is about $5.9-6.2 \mathrm{~km} / \mathrm{s}$. There is a low-velocity (about $5.80-6.00 \mathrm{~km} / \mathrm{s}$ ) layer with a thickness of 3-5 km at the depth of $12 \mathrm{~km}$ in the lower part of the upper crust. The lower crust is about $13 \mathrm{~km}$ thick, and its velocity is about $6.2-6.9 \mathrm{~km} / \mathrm{s}$. The depth of Moho is about $30 \mathrm{~km}$. The average crustal velocity is about $6.25 \mathrm{~km} / \mathrm{s}$ (Liao et al, 1988; Chen et al, 1988). In general, a relatively simple crustal structure is found in South China tectonic block region, where tectonic and seismic activities are weak. The western part of the South China tectonic block region, where the crust is relatively thick, behaves as a stable tectonic block. Thinning of the crust in the eastern part during Yanshan-Himalaya period may be attributed to the upwelling of mantle materials.

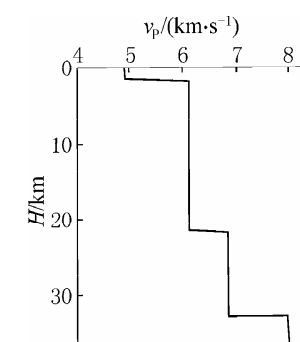

(a)

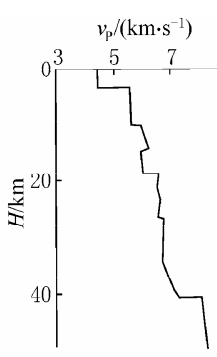

(b)

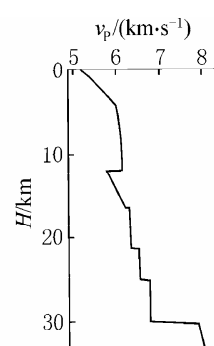

(c)
Figure 5 Typical velocity-depth functions of the crust in South China tectonic block region. (a) The South China tectonic block as a whole; (b) The northern margin; (c) The southeastern coasts.

\subsection{Crustal velocity structure in the North China tectonic block region}

The North China tectonic block region consists of Ordos, North China plain and East Shandong-Yellow Sea tectonic blocks. About 30 wide angle reflection and refraction profiles, totaling $20000 \mathrm{~km}$ in length, have been carried out in this region and its adjacent areas since the 1970s (Zhang et al, 2000; Jia and Zhang, 2005a). Different structural features of the crust have been revealed among the tectonic blocks of the region.

\subsubsection{Ordos tectonic block}

The Ordos tectonic block is relatively stable, where no distinct active tectonics has been found. Figure $6 \mathrm{a}$ shows the typical velocity-depth function of the crust in the block, which indicates a relatively simple structure. The depth of the basement is about $3-5 \mathrm{~km}$. The thicknesses of the upper crust and lower crust are about $25 \mathrm{~km}$ and $15-19 \mathrm{~km}$, respectively; the velocities are $6.00-6.30 \mathrm{~km} / \mathrm{s}$ and $6.50-6.90 \mathrm{~km} / \mathrm{s}$ respectively. The Moho behaves as a sharp velocity discontinuity. The thickness of the crust as a whole is about $41 \mathrm{~km}$, and its average velocity is about $6.30-6.40 \mathrm{~km} / \mathrm{s}$. Research results show that there are no indications of volcano activities or magma intrusions, no strong earthquakes have occurred and micro-earthquake activity is very weak inside Ordos tectonic block. The results of wide angle reflection and refraction experiments indicate that there is no low velocity distribution in the crust, the average velocity of the crust is relatively high and the layered structure of the crust is simple, besides no distinct fluctuations of the crustal interfaces or Moho have been found. All of these structural features point to a stable crust in Ordos tectonic block (Zhang et al, 2003; Zhang and Wang, 1984; Liu, 1996; Jia and Zhang, 2005a; Zhao et al, 2005, 2009).

\subsubsection{North China plain tectonic block}

A series of normal faults and grabens in N-NE strike have been formed as a result of the thinning of North China craton lithosphere and magma upwelling since Mesozoic era, leading to complicated tectonics. Several destructive earthquakes have occurred in this region, including Xingtai earthquake in 1966 and Tangshan earthquake in 1976. There are some uplifts and rift basins in North China tectonic block region (Zhang et al, 2002; Duan et al, 2002; Wang et al, 2004; Jia et al, $2005 \mathrm{~b}$ ), and their deformation features are different from each other. Figure $6 \mathrm{~b}$ shows the velocity-depth function of the crust in Taihang uplift of the North China plain, which indicates the crustal structure in North China plain is more complicated than that in Ordos tectonic block. The depth of the basement is about $1-2 \mathrm{~km}$. The thickness of the upper crust is about $27 \mathrm{~km}$, and its velocity is about $6.00-6.40 \mathrm{~km} / \mathrm{s}$. There are slightly low velocity distributions in the middle part of the crust and the crust-mantle transition zone. The thickness of the crust is about $42 \mathrm{~km}$, and the average crustal velocity is about $6.20 \mathrm{~km} / \mathrm{s}$. The crustal structure in Taihang uplift is characterized by shallow basement, stable velocity and inconspicuous low velocity distribution. The feature of inconspicuous low velocity distribution in the crust may be related to the thickening and rising of the crust in this region which resulted in structurally decoupling 
deformation.

Figure $6 \mathrm{c}$ shows the typical velocity-depth function of the crust in the depression areas of North China. The basement is about $6 \mathrm{~km}$ deep. The upper crust, which consists of alternately low and high velocity layers, is about $21 \mathrm{~km}$ thick. The thickness of the lower crust is about $7 \mathrm{~km}$, and its average velocity is about 6.10-7.20 $\mathrm{km} / \mathrm{s}$. The crust-mantle transition zone consists of alternately low and high velocity laminas. The thickness of the crust is about $30 \mathrm{~km}$, and the average crustal velocity is about $5.80 \mathrm{~km} / \mathrm{s}$, which is obviously lower than the average crustal velocity in normal crust. The velocity structure of the crust suggested that this region underwent the process of upwelling of mantle-derived materials, thinning of the crust, rifting of the surface and thickening of the sediments in the depression areas, which resulted from North China craton destruction since Mesozoic era.

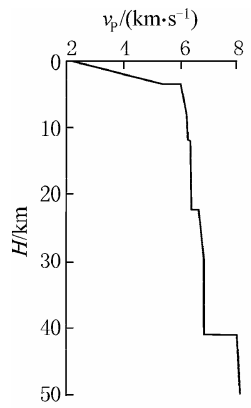

(a)

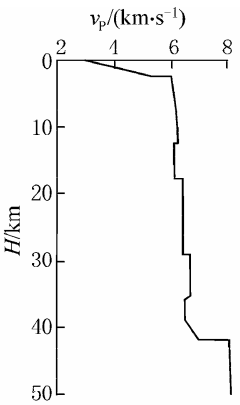

(b)

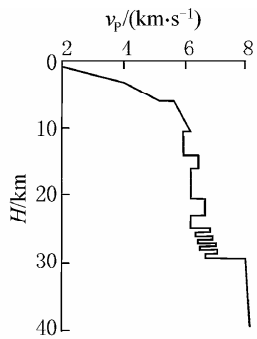

(c)

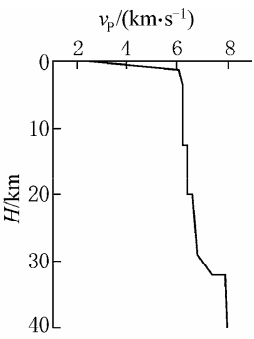

(d)

Figure 6 Typical velocity-depth functions in North China active tectonic block region. (a) Ordos tectonic block; (b) Taihang uplift; (c) Middle Hebei depression; (d) East Shandong and the Yellow Sea.

\subsubsection{East Shandong-Yelbo Sea tectonic block}

The East Shandong-Yellow Sea tectonic block, a relatively stable tectonic block, belongs to Yangtze platform. Figure 6d shows the typical velocity-depth function of the crust in this region. The depth of the basement is about $2-3 \mathrm{~km}$; the thickness of the upper crust is about $23 \mathrm{~km}$, and its velocity is about $6.10 \mathrm{~km} / \mathrm{s}$. The Moho is about $32 \mathrm{~km}$ deep. The crustal velocity structure is relatively simple. The crustal velocity increases with depth, and it reflects the basic features of platforms.

\subsection{Northeastern Asia tectonic block region}

The Northeastern Asia active tectonic block region consists of three active tectonic blocks, namely, Yan Shan Mountains, Xing'an-East Mongolia and Northeast China tectonic blocks. It is a relatively stable region of tectonic activity, where Cenozoic tectonic deformation is weak and interior differential movement isn't obvious, except for the occurrence of deep earthquakes (300-600 $\mathrm{km}$ deep) in the boundary area between China and Korea and some volcanic activities. Some deep seismic sounding experiments have been carried out, including the Manzhouli-Suifenhe geoscience transect (Fu et al, 1998), the East Ujimqinqi of Inner Mongolia-Donggou of Liaoning province geoscience transect (Lu and Xia, 1993) and deep seismic sounding investigation into the deep structure of magma system in Changbaishan Tianchi volcanic region (Zhang et al, 2002a).

\subsubsection{Yan Shan Mountains tectonic block}

The Yan Shan Mountains tectonic block joins up with the North China tectonic block, and its crustal structure is similar to the structures of Taihang and Yin Shan Mountains rifts (Figure 7a). The basement is relatively shallow, and its depth is about $2 \mathrm{~km}$. The thickness of the upper crust is about $28 \mathrm{~km}$, and the velocity is about $6.10-6.20 \mathrm{~km} / \mathrm{s}$ (Jia and Zhang, 2005a). The velocity of the lower crust is about $6.30 \mathrm{~km} / \mathrm{s}$. The thickness of the crust is $40 \mathrm{~km}$. A weak negative velocity gradient layer exists in the crust, which may be related to the tectonic deformation during thickening and rising of the crust.

\subsubsection{Xing'an-East Mongolia tectonic block}

The Xing'an-East Mongolia tectonic block is located at the contact area between Eurasian plate and the stable Siberia plate. The results of DSS data (Lu and Xia, 1993) show that its crustal velocity structure behaves as the structure of stable platforms. The basement is about 3-4 km deep, and the velocity gradually increases with depth (Figure 7b). The thickness of the upper crust is about $24 \mathrm{~km}$. The velocities of the upper and lower crust are about $6.10-6.40 \mathrm{~km} / \mathrm{s}$ and $6.80-6.90 \mathrm{~km} / \mathrm{s}$ respectively, and the thickness of the Moho is about $36 \mathrm{~km}$ 
(Figure 7b).

\subsubsection{Northeast China tectonic block}

The Northeast China tectonic block consists of several micro tectonic blocks with different eras and different sources under the action of a uniform external force ( $\mathrm{Fu}$ et al, 1998), namely, Eerjina-Daxinganling, Songjiang, Jiamusi and Xingkai micro tectonic blocks. These micro tectonic blocks are separated by suture zones. Some sinistral slip faults and basins, such as Hailaer basin and Songliao basin, were formed as a result of the NNW subduction of the west Pacific plate. Figure $7 \mathrm{c}$ shows the typical velocity-depth function of the crust in Songliao basin, where the depth of the basement varies obviously, the greatest reaching 7-8 km. The thickness of the upper crust is about $22-25 \mathrm{~km}$, and the velocity is about $6.2-6.3 \mathrm{~km} / \mathrm{s}$. There is a low velocity layer with a velocity of $6.0 \mathrm{~km} / \mathrm{s}$ in the upper crust. The thickness of the lower crust is about $5-10 \mathrm{~km}$ and the velocity is about $6.8 \mathrm{~km} / \mathrm{s}$. Figure $7 \mathrm{~d}$ shows the typical velocity-depth function of the crust inside the micro tectonic blocks. The basement is shallower in the micro tectonic blocks than in Songliao basin. The thickness of the upper crust is about $23-25 \mathrm{~km}$, and the velocity is about $6.2-6.4 \mathrm{~km} / \mathrm{s}$ there. There is a smaller scale low velocity distribution in the upper crust. The thickness of the lower crust is about $11-15 \mathrm{~km}$, and the velocity is about $6.5-6.8 \mathrm{~km} / \mathrm{s}$. The thickness of the crust in the micro tectonic blocks is $34-37 \mathrm{~km}$, which is greater than that in Songliao basin.

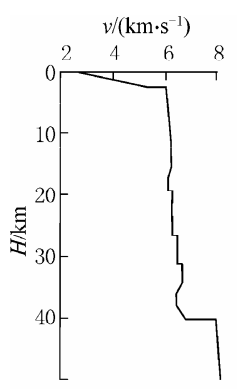

(a)

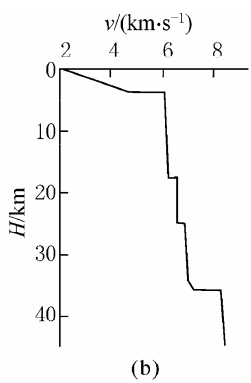

(b)

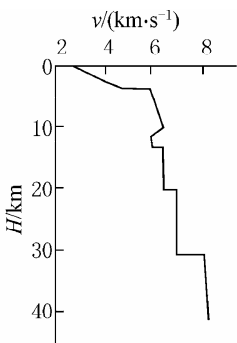

(c)

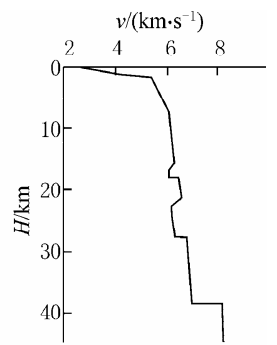

(d)

Figure 7 Typical velocity-depth functions of the crust in Northeastern Asia active tectonic block region. (a) Yan Shan Mountains tectonic block; (b) Xing'an-East Mongolia tectonic block; (c) Northeast China tectonic blocks; (d) Micro tectonic blocks.

\subsection{Xiyu tectonic block region}

The Xiyu tectonic block region includes Tarim, Tian Shan Mountains and Junggar active tectonic blocks The wide angle reflection and refraction profiles carried out in this region include Tashikuergan-Jiashi-Aheqi, Maigaiti-Artux-Tuoyun (Zhang et al, 2002b), Shaya-Buerjin (Zhang et al, 2000) and Kuerle-Jimusaer (Zhao et al, 2005) profiles.

\subsubsection{Tarim tectonic block}

Figure 8a shows the typical velocity-depth function of the crust in Tarim basin. Tarim basin underwent a long time sedimentary process, and the thickness of sediments is about $10 \mathrm{~km}$. The upper crust there is about $40 \mathrm{~km}$ deep, and the velocity is about $6.10-6.50 \mathrm{~km} / \mathrm{s}$. The thickness of the lower crust is about $20 \mathrm{~km}$, and its velocity is $6.70-6.90 \mathrm{~km} / \mathrm{s}$. The thickness of the crust as a whole is $60 \mathrm{~km}$. The structure of the crust in Tarim basin is characterized by obvious stratification and high crustal average velocity $(6.50 \mathrm{~km} / \mathrm{s})$ (Zhang et al, 2002b; Zhao et al, 2002; Liu et al, 2003). The results indicate that Tarim tectonic block behaves as a stable tectonic block, which underwent fewer geological reforming actions, but the crustal structure is complicated in its contact part with Tian Shan tectonic zone on the north and Pamirs tectonic arc on the northeast, where Jiashi earthquake occurred.

\subsubsection{Tian Shan Mountains tectonic block}

The Tian Shan Mountains orogenic zone is located at the place between the ancient and stable Tarim and Junggar tectonic blocks, which not only is affected by the collisions from India and Eurasia plates, but also suffers the southward press action of Siberia plate. The Tian Shan Mountains area and its boundaries underwent strong tectonic movement of the crust and strong seismicity. Its velocity-depth function of the crust (Figure 8b, Zhao et al, 2005) shows the depth of crystalline basement varies obviously, the average being about $6 \mathrm{~km}$. The thickness of the upper crust is about $32 \mathrm{~km}$ and there are low velocity distributions with a velocity of $5.50 \mathrm{~km} / \mathrm{s}$. The lower crust is relatively thick and its velocity is about $6.40-7.00 \mathrm{~km} / \mathrm{s}$. 
The Moho is $56 \mathrm{~km}$ deep there, and it is obviously deeper than the Moho in its adjacent areas. The low velocity structure of the crust is very conspicuous in Tian Shan Mountains tectonic zone, with an average crustal velocity of only $6.10 \mathrm{~km} / \mathrm{s}$. It is inferred that Tian Shan Mountains block is characterized by "soft" crust. Another noticeable feature of this region is that a special low velocity $(6.80-7.20 \mathrm{~km} / \mathrm{s})$ layer exists in the uppermost mantle. This low velocity layer could be explained by the diving of Tarim and Junggar tectonic blocks, which brought crustal materials into the Tian Shan Mountains tectonic block, so that a "double lower crust" was formed (Zhang et al, 2000; Zhao et al, 2005).

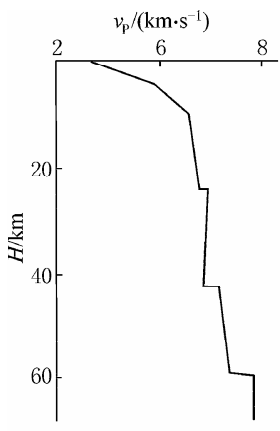

(a)

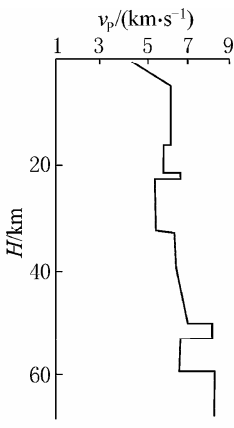

(b)

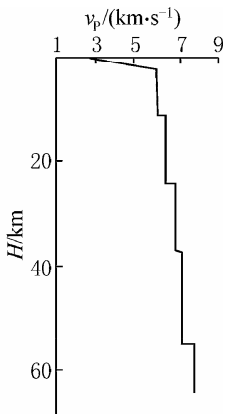

(c)
Figure 8 Typical velocity-depth functions of the crust in Xiyu tectonic block region. (a) Tarim tectonic block; (b) Tian Shan Mountains tectonic block; (c) Junggar tectonic block.

\subsubsection{Junggar tectonic block}

Junggar tectonic block is located between the northern Tian Shan Mountains and Altay fold zone. The crustal structure of Junggar tectonic block is distinctly different from that of Tian Shan Mountains. Figure 8c shows the typical velocity-depth function of the crust in Junggar tectonic block, which reveals good layered property of the upper crust, with a depth of about $38 \mathrm{~km}$. The velocity increases with depth generally, but weak velocity inverse exists in the upper crust, and its value is about $6.10-6.40 \mathrm{~km} / \mathrm{s}$. Lateral variation of velocities isn't obvious in the lower crust. The thickness of the crust is about $55 \mathrm{~km}$, and the average velocity of the crust is about $6.50 \mathrm{~km} / \mathrm{s}$. There are some weak low velocity distributions in the crust, and a large number of active faults distribute around Junggar tectonic block (Qu et al, 2008a, b; Zhang et al, 2008b).

\subsection{Yunnan-Burma active tectonic block region}

The Yunnan-Myanmar tectonic block region, located south of Qinghai-Tibet plateau tectonic knot, includes the west part of Yunnan province of China,
Myanmar and Vietnam. Strong earthquakes frequently occurred in this region. Its western boundary is the Myanmar arcuate subduction belt. India plate obliquely dived into Myanmar arcuate mountains, forming a right-lateral strike slip fault zone in north-south strike, which controlled the occurrence of a series of strong earthquakes. Its eastern boundary is Jinshajiang-Honghe fault zone. The tectonic block region can be divided into two active tectonic blocks, i.e., West Yunnan and South Yunnan tectonic blocks, with Nujiang-Lancangjiang fault as the boundary. The wide angle reflection and refraction experiments carried out in this region include DSS 87 of Yunnan, DSS 8687 of Yunnan (Hu et al, 1986; Yan et al, 1985; Kan et al, 1986; Lin et al, 1993) and the study of crustal structure and magma system in Tengchong volcanic area (Wang et al, 2002).

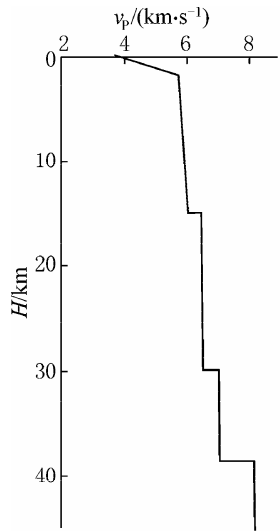

(a)

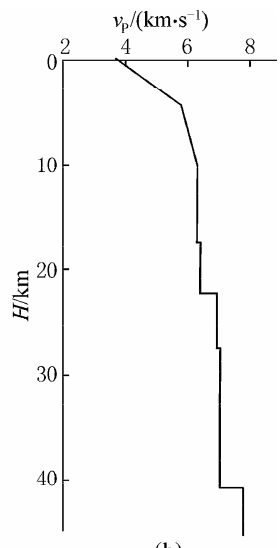

(b)
Figure 9 Typical velocity-depth functions of the crust in Yunnan-Myanmar tectonic block region. (a) West Yunnan; (b) South Yunnan.

Figure 9 shows the typical velocity-depth functions of West and South Yunnan tectonic blocks, respectively. The thickness of the crystalline basement is about $3 \mathrm{~km}$ in West Yunnan, and it is slightly deeper in the basin region. The thickness of the upper crust is about $29 \mathrm{~km}$, and the velocity is about $5.90-6.40 \mathrm{~km} / \mathrm{s}$. The lower crust behaves as a weak velocity gradient layer, in which the velocity is about $6.90-7.00 \mathrm{~km} / \mathrm{s}$. The Moho is about $39 \mathrm{~km}$ deep. In South Yunnan, the thickness of the crystalline basement is about $5 \mathrm{~km}$. The thickness of the upper crust is about $27 \mathrm{~km}$, and the velocity is about $6.00-6.50 \mathrm{~km} / \mathrm{s}$. The lower crust also behaves as a weak velocity gradient layer, in which the velocity is about $6.90-7.00 \mathrm{~km} / \mathrm{s}$. The Moho is about $42 \mathrm{~km}$ deep, and the average crustal velocity is about $6.20 \mathrm{~km} / \mathrm{s}$. In general, the velocity of the crust increases with depth in Yun- 
nan-Myanmar active tectonic block region, but there are some low velocity distributions in the margin area of this region, such as in the northern area of Honghe fault zone (Lin et al, 1993).

\section{Discussion and conclusions}

The results of deep seismic sounding experiments carried out on the Chinese mainland have shown the basic crustal structure features of different tectonic blocks and the structural differences among them, which are manifested mainly in layered features of the crust, structural features of the upper and lower crust, scales of heterogeneity of crustal structures and topography of interfaces. These results can help to understand some geoscience problems, such as tectonic evolutions of different tectonic blocks, relations between shallow and deep structures and deep structural backgrounds of earthquake occurrences.

1) The crustal structure is relatively simple in stable tectonic blocks, such as Ordos tectonic block. In general, there is no low velocity distribution in the crust, crustal average velocity is relatively high and the Moho behaves as a sharp discontinuity in stable tectonic blocks. Seismic activity is usually weak in such blocks.

2) The velocity structure of the crust is complicated, low velocity distributions usually exist in the crust and the average crustal velocity is lower in the tectonic blocks which underwent complicated tectonic motions, such as North China plain tectonic block.

3) The structural features of the crust in the transition zones among different tectonic blocks are related to the tectonic motion features and crustal medium properties of their adjacent tectonic blocks. Distinct lateral variations of the crustal structure usually occur in such transition zones, which reflect strong crustal deformation and the variation of material conditions of the crust resulting from strong tectonic motions. Strong earthquakes on the Chinese mainland usually occurred in this kind of regions, for example, Wenchuan $M_{\mathrm{S}} 8.0$ earthquake in 2008 occurred in Longmenshan tectonic zone, which is located in the tectonic transition zone between Qinghai-Tibet and South China tectonic blocks.

4) Crustal structures are closely related to tectonic movements. The study of crust structures can help understand the evolution process of tectonic movement and its influences.

\section{References}

Chen X B, Wu Y Q, Du P S, Li J S, Wu Y R, Jiang G F and Zhao J X (1988).
Crustal velocity structure at the two sides of Longmenshan tectonic belt. In: Department of Scientific Programming and Earthquake Monitoring ed. Developments in the Research of Deep Structure of China's continent. Geological Publishing House, Beijing, 97-113 (in Chinese).

Cui Z Z,Yin Z X, Gao E Y, Lu D Y and Fu W Z (1990). The structure and tectonics of the crust and their relation with earthquake in the Qinghai-Tibet Plateau. Acta Geosicientia Sinica 21: 215-226 (in Chinese with English abstract).

Duan Y H, Zhang X K and Fang S M (2002). Three-dimensional finite-difference tomography of velocity structure of the upper crust in North China. Chinese J Geophys 45(3): 362-369 (in Chinese with English abstract).

Fu W Z, Yang B J, Liu C, Kgylov S V (1998). Study on the seismology in Manzhouli-Suifenhe geoscience transect of China. Journal of Changchun University of Science and Technology 36(6): 765-772 (in Chinese with English abstract).

Gao R, Ma Y S, Li Q S, Zhu X, Zhang J S, Wang H Y, Li P W, Lu Z W and Guan Y (2006). Structure of the lower crust beneath the Songpan block and West Qinling orogen and their relation as revealed by deep seismic reflection profiling. Geological Bulletin of China 25(12): 1361-1367 (in Chinese with English abstract).

Hu H X, Lu H X, Wang C Y, He Z Q,Zhu L B, Yan Q Z, Fan Y X, Zhang G Q and Deng Y E (1986). Explosion investigation of the crustal structure in western Yunnan Province. Chinese J Geophys 29(2): 133-144 (in Chinese with English abstract).

Jia S X and Zhang X K (2005a). Crustal structure and comparison of different tectonic blocks in North China. Chinese J Geophys 48(3): 611-620 (in Chinese with English abstract).

Jia S X, Qi C, Wang F Y, Chen Q F, Zhang X K and Chen R (2005b). Three-dimensional crustal gridded structure of the Capital area. Chinese $J$ Geophys 48(6): 1 316-1 324 (in Chinese with English abstract).

Kan R J, Hu H X, Zeng R S, Mooney W D and Mcevilly T V (1986). Crustal structure of Yunnan Province, People's Republic of China, from seismic refraction profiles. Science 234: 433-437.

Li S L, Zhang X K, Zhang C K, Zhao J R and Cheng S X (2002). A preliminary study on the crustal velocity structure of Maqin-Lanzhou-Jingbian by means of deep seismic sounding profile. Chinese J Geophys 45(2): 210-217 (in Chinese with English abstract).

Liao Q L, Wang Z M, Wang P L, Yu Z K, Wu N Y and Liu B C (1988). Explosion seismic study of the crustal structure in Fuzhou-Quanzhou-Shantou region. Chinese J Geophys 31(3): 270-280 (in Chinese with English abstract).

Liao Q L, Wang Z M, Qiu T X, Yuan D Q, Wang H T, Wu N Y and Liu B C (1990). Preliminary research of the crustal structure in Fuzhou basin and its adjacent area. Acta Geophysica Sinica 33(2): 163-173 (in Chinese with English abstract).

Lin Z X, Hu H X, Zhang W B, Zhang H F, He Z Q, Lin Z M and Qiu T X (1993). The study of velocity structure character for crust and upper-mantle in West Yunnan, China. Acta Seismologica Sinica 15(4): 427-440 (in Chinese with English abstract).

Liu H F (1996). Cycle-geodynamic scenario and evolution of sedimentary basins in China. Earth Science-Journal of China University of Geosciences 21(4): 345-356 (in Chinese with English abstract).

Liu H B, Teng J W and Yin Z X (1990). Characteristics of the 2-D crustal structure and fault distribution beneath the Seiling Co-Yangamdo in the northern Tibet Plateau. Acta Geosicientia Sinica 21: 259-267 (in Chinese with English abstract).

Liu Z, Zhang X K, Zhou X S, Zhao J R, Zhang C K and Pan J S (2003). Study of crustal structure in terms of physical property and discussion on seismogenic environment in the northeastern Pamirs. Acta Seismologica Sinica 25(3): 242-249 (in Chinese with English abstract).

Lu D Y and Wang X J (1990). The crustal structure and deep internal processes in the Tuotuohe-Golmud area of the north Qinghai-Tibet Plateau. Acta Geosicientia Sinica 21: 227-238 (in Chinese with English abstract).

Lu Z X and Xia H K (1993). Geoscience transest from east Ujimqinqi, Inner Mongolia, to Donggou, Liaoning, China. Acta Geophysica Sinica 36(6): 765-772 (in Chinese with English abstract). 
Qu G S, Ma Z J, Zhang N, Li T and Tian Y (2008a). Fault structure in and around Junggar basin. Xinjiang Petroleum Geology 29(3): 290-295.

Qu G S, Ma Z J, Shao X Z and Zhang X K (2008b). Basement and crust structure in Junggar Basin. Xinjiang Petroleum Geology 29(6): 669-674.

Teng J W (1985). The conspectus of geophysical study on the crust structure in Qinghai-Tibet Plateau. Acta Geophysica Sinica 28(Supp): 1-15 (in Chinese with English abstract).

Wang C Y, Lou H, Wu J P, Bai Z M, Huang F G and Qin J Z (2002). Seismological study on the crustal structure of Tengchong volcano-geothermal area. Acta Seismologica Sinica 24(3): 231-242 (in Chinese witn English abstract).

Wang C Y, Han W B, Wu J P, Lou H and Bai Z M (2003). Crustal structure beneath the Songpan-Garze orogenic belt. Acta Seismologica Sinica 25(3): 229-241 (in Chinese with English abstract).

Wang F Y, Zhang X K, Chen Y, Li L, Chen Q F, Zhao J R, Zhang J S and Liu B $F$ (2004). 2-D P-wave velocity structure in the mid-east segment of Zhangjiakou-Bohai tectonic zone: Anxin-Xianghe-Kuancheng DSS profile. Acta Seismologica Sinica 26(Supp): 31-41 (in Chinese with English abstract).

Wu G J, Gao R and Yu Q F (1991). Integrated investigations of the Qinghai-Tibet Plateau along the Yadong-Golmud Geoscience Transect. Chinese $J$ Geophys 34(5): 552-561 (in Chinese with English abstract).

Yan Q Z, Zhang G Q, Hu H X and Han R J (1985). Crustal structure along Simao-Malong profile in Yunnan Province. Seismological Research 8(2): 249-280.

Yin Z X, Teng J W and Liu H B (1990). The 2-D crustal structure study in the Yadong-Damxung region of the Tibet Plateau. Acta Geosicientia Sinica 2l: 239-246 (in Chinese with English abstract).

Yin Z X, Lai M H, Xiong S B, Liu H B, Teng J W and Kong X R (1999). Crustal structure and velocity distribution from deep seismic sounding along the profile of Lianxian-Boluo-Gangkou in South China. Chinese $J$ Geophys 42(3): 383-392 (in Chinese with English abstract).

Yuan D Y, Zhang P Z, Liu B C, Gan W J, Mao F Y, Wang Z C, Zheng W J and Guo $H$ (2004). Geometrical imagery and tectonic transformation of Late Quaternary active tectonics in northeastern margin of Qinghai-Tibet Plateau. Acta Geologica Sinica 78(2): 270-278 (in Chinese with English abstract).

Zhang C K, Zhang X K, Zhao J R, Ren Q F, Zhang J S and Hai Y (2002). Study and review on crust-mantle velocity structure in Bohai Bay and its adjacent areas . Acta Seismologica Sinica 24(4): 428-435 (in Chinese with English abstract).

Zhang P Z, Deng Q D, Zhang G M, Ma J, Gan W J, Min W, Mao F Y and Wang Q (2003). The strong earthquake activity in continental China and active block. Science in China (Series D) 33(Supp): 12-20 (in Chinese with English abstract)

Zhang X K, Zhang C K, Jia S X, Yang Z X, Zhao J R, Fang S M, Zhao J M, Yang J, Duan Y H, Song Z L and Deng H Z (2000). The structure of the crust at the Tianshan and its dynamics meaning. In: Zhou G Z ed. Proceedings of 2000 Symposium, China Science Press, Beijing, 556-557 (in Chinese)
Zhang X K, Zhang C K, Zhao J R, Yang Z X, Li S L, Zhang J S, Liu B F, Cheng S X, Sun G W and Pan S Z (2002a). Deep seismic sounding investigation into the deep structure of the magma system in Changbaishan Tianchi volcanic region. Acta Geophysica Sinica 24(2): 135-143 (in Chinese with English abstract).

Zhang X K, Zhao J R, Zhang C K, Ren Q F, Nie W Y, Cheng S X, Pan S Z and Tang Z Q (2002b). Crustal structure at the northeast side of the Pamirs. Chinese J Geophys 45(5): 665-671 (in Chinese with English abstract).

Zhang X K, Li S L, Wang F Y, Jia S X and Fang S M (2003). Differences of crustal structures in northeastern edge of Tibet Plateau, Ordos and Tangshan earthquake region in north China--results of deep seismic sounding. Seismology and Geology 25(1): 52-60 (in Chinese with English abstract).

Zhang X K, Yang Z X, Xu Z F, Pan J S, Liu Z, Wang F Y, Jia S X, Zhao J R, Zhang C K and Sun G W (2007). Upper crust structure of eastern A'nyemaqen suture zone: Results of Barkam-Luqu-Gulang deep seismic sounding profile. Acta Seismologica Sinica 29(6): 592-604 (in Chinese with English abstract)

Zhang X K, Jia S X, Zhao J R, Zhang C K, Yang J, Wang F Y, Zhang J S, Liu B F, Sun G W and Pan S Z (2008a). Crustal structures beneath west Qinling-east Kunlun orogen and its adjacent area--results of wide-angle seismic reflection and refraction experiment. Chinese J Geophys 51(2): 439-450 (in Chinese with English abstract).

Zhang X K, Qu G S and Zhao J R (2008b). Seismic detection of deep structure in Junggar Basin. Xinjiang Petroleum Geology 29(6): 675-679.

Zhang Y M and Wang L M (1984). On the Meso-Cenozoic tectonic dynamic characteristics in the North China fault block region. In: Institute of Geology, Chinese Academy of Sciences ed. Formation and Development of the North China Fault Block Region. Science Press, Beijing, 143-157 (in Chinese).

Zhao J R, Zhang X K, Zhang C K, Ren Q F, Cheng S X, Zhang J S,Nie W Y and Pan S Z (2002). The detection and research of the deep crust tectonic characters at the Jiashi-Artux seismic region. Earthquake Research in China 18(4): 317-325 (in Chinese with English abstract).

Zhao J R, Li S L, Zhang X K, Yang Z X, Zhang C K, Liu B F, Zhang J S and Pan S Z (2005). Three dimensional Moho geometry beneath the northeast edge of the Qinghai-Tibet Plateau. Chinese J Geophys 48(1): 78-85 (in Chinese with English abstract).

Zhao J R, Zhang X K, Wang F Y, Zhang C K, Zhang J S, Liu B F and Pan S Z (2009). North China sub-craton lithospheric structure elucidated through coal mine blasting. Chinese Science Bulletin 54(7): 669-676 (in Chinese with English abstract).

Zhao J M (2005). Lithospheric Structure and Geodynamics of Tianshan Orogenic Belt. Seismological Press, Beijing, 23-85 (in Chinese).

Zhu J F, Xu X W, Zhang X K, Huang Z L, Chen X X, Fang S M, Liu B J and Zheng R Z (2005). Joint exploration of crustal structure in Fuzhou basin and its vicinities by deep seismic reflection and high resolution refraction as well as wide-angle reflection/refraction. Science in China (Series D) 35(8): 738-749 (in Chinese with English abstract).

Zhu J F, Fang S M, Zhang X K, Qu G S, Huang Z L, Hong X, Liu B J, Yang Z $X$ and Duan Y H (2006). Exploration and study of deep crustal structure in the Quanzhou basin and its adjacent area. Earthquake Research in China 22(4): 405-417 (in Chinese with English abstract). 